\title{
Recent perspectives on temporary river ecology
}

\author{
Thibault Datry $\cdot$ David B. Arscott $\cdot$ Sergi Sabater
}

Received: 5 September 2011/Accepted: 4 October 2011/Published online: 11 October 2011

(C) Springer Basel AG 2011

Temporary rivers, rivers that periodically cease flowing, have been reported from all continents and all types of climates. They represent a substantial proportion of the total number, length and discharge of the world's rivers (Larned et al. 2010) and are the dominant freshwater type in Southern Europe (Tockner et al. 2009). The number and length of temporary rivers are projected to increase in regions likely to experience drying trends related to climate change and increases in water abstraction for socio-economic uses (Larned et al. 2010; Sabater and Tockner 2010). As a consequence of the growing concern over water quantity and increased incidences of perennial rivers shifting to intermittent conditions, there is a renewed and urgent need to better understand the ecological structure and function of temporary rivers. Particularly important is the development of quantitative relationships that will better serve predictive models aimed at estimating biological and biogeochemical responses to increased frequency and

T. Datry $(\bowtie)$

Cemagref, UR-MALY, 3 bis quai Chauveau,

69336 Lyon cedex 09, France

e-mail: thibault.datry@cemagref.fr

D. B. Arscott

Stroud Water Research Center, Avondale, PA, USA

e-mail: darscott@stroudcenter.org

\section{S. Sabater}

Catalan Institute for Water Research (ICRA), H2O Building,

Scientific and Technologic Park of the UdG, Emili Grahit 101,

17003 Girona, Spain

e-mail: sergi.sabater@udg.edu

\section{S. Sabater}

Faculty of Sciences, Institute of Aquatic Ecology,

University of Girona, Campus Montilivi,

17071 Girona, Spain duration of drying or, alternatively, decreasing intermittency that may accompany water resources management after impoundment (e.g., for irrigation) (Datry et al. 2007; Arscott et al. 2010). As a result, the number of studies focusing on temporary rivers has grown exponentially in the past 20 years (Fig. 1). On average, about 20-25 papers focusing on temporary rivers have been published annually for the last 4-5 years, half of them in the field of biology and ecology (Fig. 1).

In an attempt to synthesise the recent advances and perspectives on temporary river ecology, we organised a special session during the 2010 annual meeting of the North American Benthological Society in Santa Fe, NM, USA, an area where temporary rivers are common features of the landscapes. Those presentations and ensuing discussions among the session attendees ultimately stimulated the organisation of this special issue on temporary river ecology in Aquatic Sciences.

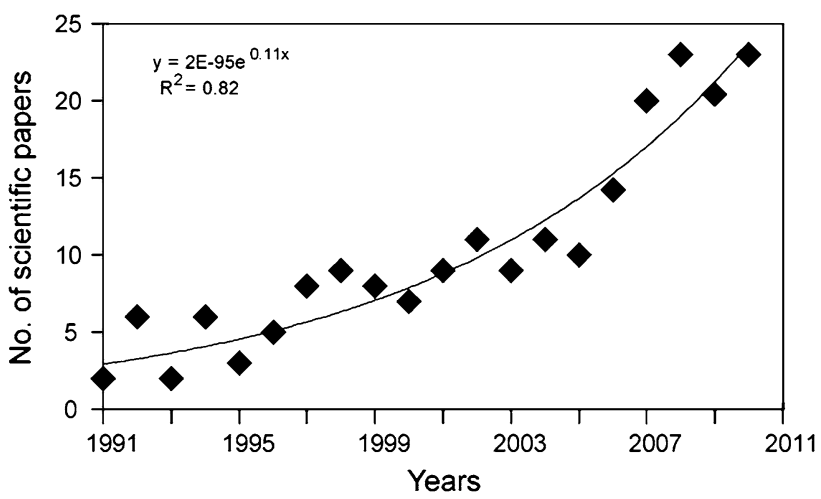

Fig. 1 Number of scientific manuscripts published per year since 1990 resulting from a query of the Web Of Science (http:// webofknowledge.com/) performed in April 2011 using the search term "river and temporary or intermittent or ephemeral" 


\section{Scope of the special issue}

The 11 contributions included in this special issue include a diverse array of disciplines studying temporary river ecology including stream biogeochemistry and organic matter processing, aquatic and terrestrial invertebrate ecology, and fish ecology. All of these studies also incorporate a hydrological understanding of the study systems and in many cases utilize hydrological statistics to help explain ecological pattern and processes occurring in these temporary rivers.

Alternating dry and wet phases of temporary rivers influence the quantity and quality of organic matter and nutrients in temporary rivers. For example, Ylla et al. (2011) measured changes in amino acid composition and concentration of dissolved and particulate organic matter (in various benthic compartments) as their study river system dried and re-wetted. Dissolved organic matter in transport prior to stream drying had an amino acid signature that indicated it was more labile and mostly microbially-derived compared to a more recalcitrant and terrestrially-derived amino acid signature of DOM after stream re-wetting. In contrast, amino acid composition in the various benthic compartments was more stable than DOM in transport. As another example of how wet and dry phases influence biogeochemistry, Von Schiller et al. (2011) described how stream nutrient availability changed during ecosystem contraction, fragmentation and expansion. They observed marked temporal changes in inorganic and organic $\mathrm{N}$ and $\mathrm{P}$ concentrations and in stoichiometric ratios. Results from both of these studies emphasize the importance of flow intermittence in regulating stream nutrient availability and its implications for nutrient management along temporary rivers.

Another study included here (Dieter et al. 2011) demonstrates that leaf litter decomposition is strongly influenced by repeated cessations of flow in temporary rivers. They found that leaf litter collected from either the dry streambed or from remnant pools were preconditioned to decomposition by UV radiation or wet-anoxic conditions, respectively. This preconditioning resulted in reduced leaf mass loss compared to freshly inundated leaves after the onset of flow. Indeed, mass loss after $\sim 45$ $\mathrm{d}$ of continuous flow was approximately 4 and $7 \%$ lower when leaves were preconditioned by irradiation and anoxic conditions, respectively. Lower chemical quality and lower living fungal biomass were measured in leaves collected from anoxic conditions. Interestingly, preconditioning had no detectable influence on the assemblage of macroinvertebrates colonizing the leaf packs. Also Corti et al. (2011) found that rates of leaf litter mass loss, microbial activity and colonization by invertebrates differed among litterbags that were continuously submerged, intermittently submerged and never submerged. Leaf litter decomposition rates decreased as submersion duration decreased, but the frequency of dry periods had no detectable influence on decomposition rate. The role of invertebrate shredders was important in explaining leaf decomposition in submerged litterbags, whereas microbial activity was most likely responsible for decomposition rates measured in dry litterbags, as terrestrial detritivores were scarce. Invertebrate shredders and microbes were both influential in decomposing leaf material from intermittently submerged litterbags. The fact that leaf litter breakdown was detectable under permanently dry conditions could be explained by alternative mechanisms such as leaching and photodegradation (Dieter et al. 2011). Datry et al. (2011) found that that dry phase duration influenced litter decomposition rates primarily because of the negative effects of the dry phase on invertebrate shredders, and that this effect extended long after rewetting, as if there was a dry event "memory". They observed that drying events affected the performance of the decomposing biota and thus the decomposition rates of leaf litter. Amongst the biota, the least resilient were the invertebrates, particularly shredders (despite the previously-described ability of some shredders to adapt to drying events, e.g., Acuña et al. 2007). In contrast to the invertebrate shredders, the microbial community tolerated drying and continued to process leaf litter during dry periods, in a manner similar to other studies (e.g., Amalfitano et al. 2008; Artigas et al. 2009).

At the interface between organic matter decomposition and invertebrate responses to drying, Fritz and Feminella (2011) examined benthic invertebrate colonization patterns on three types of buried substrata (leaves, roots, and plastic roots) over a 1-year period. Invertebrate density was significantly lower on root substrata than on plastic roots, but neither differed from densities on leaf substratum. Invertebrate biomass and richness did not vary among substrata, but invertebrate density, abundance and richness all declined between the wet and dry phases. Meiofauna and aquatic dipterans were the dominant invertebrates during the wet phase. Relative abundance of terrestrial taxa increased during the dry phase, but their absolute abundance remained lower than aquatic taxa during wet phase. These results suggest that subsurface invertebrates responded to leaves and roots as food sources, but assemblage composition was not substrate specific. Colonisation of leaves and roots within streambeds by aquatic and terrestrial taxa supports the idea that headwater intermittent streams are important interfaces for the reciprocal exchange of energy and materials between terrestrial and aquatic ecosystems.

Although the effects of flow intermittence on biota have been well-described in previous studies (e.g., Lake 2003; Matthews and Marsh-Matthews 2003; Boulton 2003), this 
special issue highlights a number of community and speciesspecific responses of aquatic and terrestrial animals to flow cessation and rewetting. Skoulikidis et al. (2011) described the effects flow cessation on a Greek river. Large sections of the river network dried during two consecutive summers, and negatively impacted fish populations, which experienced a long recovery time. However, invertebrate assemblages were more resilient and quickly recovered after the return of flow. These systems experience excessive water abstraction and their intermittency can be considered primarily artificial. Garcia-Roger et al. (2011) studied aquatic macroinvertebrates in several temporary rivers and related temporal changes in the physical habitat to changes in community structure. They quantified and characterised the physical habitat at local (substrata), reach (riffle and pools), and catchment (among streams) scales and found that changes in substrata availability and riffle-pool sequences had an overriding influence on spatial variability in macroinvertebrate assemblages. They also noted the importance of remnant pools in these temporary streams for aquatic invertebrate taxa adapted to lentic conditions.

The topic of refuges from drying for aquatic taxa is also addressed in this special issue. Although some past studies have demonstrated that the hyporheic zone is a refuge for benthic invertebrates in temporary rivers, the literature is mixed and suggests that the responses of invertebrates to drying show a considerable variability (Wood et al. 2010). The study by Stubbington et al. (2011) provides strong evidence that two non-insect taxa, Gammarus pulex and Polycelis spp. migrated down to the saturated interstices of the hyporheic zone in two UK groundwater-fed streams when availability of surface water habitat decreased. However, the refugium potential of the hyporheic zone varied spatially, and appeared to be higher at sites dominated by downwelling water. Stubbington et al. (2011) also present a conceptual model of spatial variability in the refuge capacity of the hyporheic zone during habitat contraction. Hodges and Magoulick (2011) demonstrated that the effects of flow interruption on fish in small streams are species specific. They compared the directional movement of three minnow species between river habitats (riffle and pools) during seasonal drying. Results indicated species specific responses during drying (species dependent). The observations of three fish species, all within a single family, responding differently to drying, challenge previous assumptions that most fish species respond in a general manner to flow interruption.

An often overlooked component of temporary river ecology is the importance of the dry riverbed as habitat for terrestrial organisms. In many dry rivers, lizards, snakes, birds, and invertebrates utilize the dry river bed once flow disappears. To this end, Steward et al. (2011) demonstrate that dry riverbeds provide habitat for a unique set of terrestrial invertebrates. They compared terrestrial invertebrates collected in dry riverbeds in Australia and Italy with invertebrates collected in riparian zones and found 66 out of 320 taxa identified were only collected in the dry riverbed sediments. They further discuss how anthropogenic disturbances may alter dry riverbed invertebrate communities and suggest the potential of using this unique invertebrate community as a bioindicator for quantifying degradation in temporary rivers.

\section{Research perspectives: gaps and needs in temporary river ecology}

Temporary river ecology, considered until recently as being in its infancy (Sheldon 2005; Arscott et al. 2010), has recently received increased attention by scientists and water resources managers. Compared to our understanding of perennial stream ecosystems, many important questions remain. Conceptual, empirical, and mechanistic models that may help design and direct future research and test the transferability of results across regions are still lacking (but see Larned et al. 2010; Sabater and Tockner 2010). This incomplete understanding of temporary river ecology limits our ability to provide clear management advice for temporary rivers, as the tools needed by water managers (e.g., bioindicators, transferable relationships between flow intermittence and ecosystem processes and patterns) have yet to be developed.

The contributions in this special issue contribute towards our understanding of microbial and biogeochemical processes occurring during both dry and wet phases. Linkages between flow intermittence, microbial communities, nutrient processing and organic matter quality and quantity are evident herein (Von Schiller et al. 2011; Ylla et al. 2011) and will hopefully lead to the development of predictive models for nutrient and organic carbon processing along temporary rivers that incorporate biofilm development dynamics, preconditioning of organic matter, and fluvial transport dynamics. Many questions about microbial community dynamics are still unresolved. And, as scientific tools continue to be developed and become more affordable, our understanding of microbial communities will grow to eventually link microbial community structure with the dynamics of ecosystem processes such as organic matter decomposition.

Also promising is the study of the interactions between terrestrial and aquatic components of temporary rivers. Temporary rivers could indeed be pivotal sites for exchanges between terrestrial and aquatic organic matter. From this perspective, terrestrial organic matter that accumulates on streambeds during dry phases without being rapidly decomposed (Corti et al. 2011) may play an 
important role in stream organic matter processing just after rewetting. Additionally, the consequences of low organic matter processing rates for aquatic foodwebs and ecosystem productivity deserves further investigation (Datry et al. 2011; Dieter et al. 2011). Biotic interactions (e.g., predation, competition, parasitism) among terrestrial and aquatic organisms are also still poorly-understood even though these interactions can be intense, obvious, and relatively easy to study during the drying process.

There is a clear need to better quantify resistance and resilience of temporary river organisms to either drying (aquatic organisms) or rewetting (terrestrial organisms) to provide species-specific (1) tolerance limits to desiccation or hydration, (2) refuge seeking behaviour, and (3) refuge habitat characteristics (i.e., what constitutes a safe refuge for specific organisms?). For example, of the different refuge possibilities for aquatic taxa during drying (e.g., hyporheic zone, remnant pools, adjacent ponds, moist organic substrate) what types of conditions are necessary for various species to adequately resist the lethal nature of drying (e.g., see Garcia-Roger et al. 2011; Hodges and Magoulick 2011; Stubbington et al. 2011)? Conversely, what habitat components of the dry riverbed support the diversity of terrestrial taxa (invertebrates, amphibians, mammals, birds)? This area of temporary river ecology is only beginning to be understood and is an exciting frontier, albeit it is still terra incognita (Steward et al. 2011).

Last, but not least, is a need to better understand how the spatial and temporal configurations of drying and rewetting events influence the physical habitat, ecological processes, and biodiversity within and among stream networks. For example, there is considerable variability among regions globally in the rates of drying and rewetting along temporary rivers. Skoulikidis et al. (2011) provided an extreme example of the intensity and extension of intermittency. Are there biologically relevant hydroperiod classes of temporary rivers? Do rivers that frequently dry and re-wet have a vastly different structure and function compared to seasonally dry/wet rivers? Are the biological properties of upstream drying rivers unique from downstream drying rivers or river networks that completely dry? Are temporary sections of mid-reach drying rivers generally more biologically rich and more rapidly re-colonised than these other hydrologic types of temporary rivers? All of these questions require a landscape perspective that must recognize the importance of the regional climate, geology, biogeography and human history in structuring biotic assemblages along temporary rivers.

From a management point of view, certain questions must be considered to provide water managers with tools and models to effectively manage these dynamic systems. As intermittence metrics (e.g., drying duration, drying frequency) appear to be relatively good predictors for some important ecosystem processes and biodiversity patterns (e.g., Dieter et al. 2011; Corti et al. 2011; Datry et al. 2011, Fritz and Feminella 2011; Von Schiller et al. 2011), we suggest that scientists accumulate more univariate intermittence-ecology relationships across a wide range of temporary rivers in order to test for transferability and ubiquity among catchments in these relationships. Also, most extant bioindicators have little chance to succeed in detecting anthropogenic influences on temporary rivers because of the overwhelming effects of flow intermittence on biotic communities. Therefore, experimental designs should be developed to test the applicability of these bioindicators in temporary rivers. Alternatively, terrestrial invertebrates found in dry riverbeds may represent a novel approach to assessing human-induced impacts on temporary river communities (Steward et al. 2011).

\section{References}

Acuña V, Giorgi A, Muñoz I, Sabater F, Sabater S (2007) Meteorological and riparian influences on organic matter dynamics in a forested Mediterranean stream. J North Am Benthological Soc 48:1161-1172

Amalfitano S, Fazi S, Zoppini A, Barra Caracciolo A, Grenni P, Puddu A (2008) Responses of benthic bacteria to experimental drying in sediments from Mediterranean temporary rivers. Microb Ecol 55:270-279

Arscott DB, Larned ST, Scarsbrook M, Lambert P (2010) Aquatic invertebrate community structure along an intermittence gradient: Selwyn River, New Zealand. J North Am Benthological Soc 29(2):530-545

Artigas J, Romaní AM, Gaudes A, Muñoz I, Sabater S (2009) Benthic structure and metabolism in a Mediterranean stream: from biological communities to the whole stream ecosystem function. Freshw Biol 54:2025-2036

Boulton AJ (2003) Parallels and contrasts in the effects of drought on stream macroinvertebrate assemblages. Freshw Biol 48: $1173-1185$

Corti R, Datry T, Drummond L, Larned ST (2011) Natural variation in immersion and emersion affects breakdown and invertebrate colonization of leaf litter in a temporary river. Aqua Sci. doi: 10.1007/s00027-011-0216-5

Datry T, Larned ST, Scarsbrook MR (2007) Responses of hyporheic invertebrate assemblages to large-scale variation in flow permanence and surface-subsurface exchange. Freshw Biol 52:14521462

Datry T, Corti R, Claret C, Philippe M. (2011) Leaf litter decomposition along a gradient of flow permanence in a French temporary river: the memory of drying. Aqua Sci. doi: 10.1007/s00027-011-0193-8

Dieter D, von Schiller D, Garcia-Roger EM, Sánchez-Montoya MM, Gómez R, Mora-Gómez J, Snagiorgio F, Gelbrecht J, Tockner K (2011) Preconditioning effects of intermittent stream flow on leaf litter decomposition. Aqua Sci. doi:10.1007/s00027-0110231-6

Fritz KM, Feminella JW (2011) Invertebrate colonization of leaves and roots within sediments of intermittent Coastal Plain streams across hydrologic phases. Aqua Sci. doi:10.1007/s00027-0110192-9 
Garcia-Roger EM, Sanchez-Montoya MM, Gomez R, Suarez ML, Vidal-Abarca MR, Latron J, Rieradevall M, Prat N (2011) Do seasonal changes in habitat features influence aquatic macroinvertebrate assemblages in perennial versus temporary Mediterranean streams? Aqua Sci. doi:10.1007/s00027-0110218-3

Hodges SW, Magoulick DD (2011) Refuge habitats for fishes during seasonal drying in an intermittent stream: movement, survival and abundance of three minnow species. Aqua Sci. doi:10.1007/ s00027-011-0206-7

Lake PS (2003) Ecological effects of perturbation by drought in flowing waters. Freshw Biol 48:1161-1172

Larned ST, Datry T, Arscott DB, Tockner K (2010) Emerging concepts in temporary-river ecology. Freshw Biol 55:717-738

Matthews WJ, Marsh-Matthews E (2003) Effects of drought on fish across axes of space, time and ecological complexity. Freshw Biol 48:1232-1253

Sabater S, Tockner K (2010) Effects of hydrologic alterations on the ecological quality of river ecosystems. In: Sabater S, Barceló D (eds) Water scarcity in the Mediterranean. The handbook of environmental chemistry 8:15-39

Sheldon F (2005) Incorporating natural variability into the assessment of ecological health in Australian dryland rivers. Hydrobiologia $552: 45-56$

Skoulikidis NT, Vardakas L, Karaouzas I, Economou AN, Dimitriou E, Zogaris S (2011) Assessing water stress in Mediterranean lotic systems: insights from an artificially intermittent river in Greece. Aqua Sci. doi:10.1007/s00027-011-0228-1
Steward A, Marshall JC, Sheldon F, Harch B, Choy S, Bunn S, and Tockner K (2011) Terrestrial invertebrates of dry river beds are not simply subsets of riparian assemblages. Aqua Sci. doi: 10.1007/s00027-011-0217-4

Stubbington R, Wood PJ, Reid I (2011) Spatial variability in the hyporheic zone refugium of temporary streams. Aqua Sci. doi: 10.1007/s00027-011-0203-x

Tockner K, Uehlinger U, Robinson CT, Tonolla D, Siber R, Peter FD (2009) Introduction to European Rivers. In: Tockner K, Uehlinger U, Robsinson CT (eds) Rivers of Europe. Academic Press, London $\mathrm{p} 1-23$

Von Schiller D, Acuña V, Graeber D, Marti E, Ribot M, Sabater S, Timoner X, Tockner K (2011) Contraction, fragmentation and expansion dynamics determine nutrient availability in a Mediterranean forest stream. Aqua Sci. doi:10.1007/s00027-0110195-6

Wood PJ, Boutlon AJ, Little S, Stubbington R (2010) Is the hyporheic zone a refugium for aquatic macroinvertebrates furing severe low flow condition? Fundam Appl Limnol 176(4):377-390

Ylla I, Sanpera-Calbet I, Muñoz I, Romani AM, Sabater S (2011) Organic matter characteristics in a Mediterranean stream through amino acid composition: changes driven by intermittency Aqua Sci. doi:10.1007/s00027-011-0211-x 